\section{MATERIAL SELECTION OF BLANKING TOOL BY USING A STATISTICAL METHOD}

\section{TOMAS HOLOTA ${ }^{1}$, MARIA HOLIENCINOVA ${ }^{2}$, MARTIN KOTUS $^{3}$, STEFAN MIHINA4}

1 Slovak University of Agriculture in Nitra, Faculty of Engineering, Nitra, Slovakia

2 Slovak University of Agriculture in Nitra, Faculty of Economics and Management, Nitra, Slovakia

DOI : 10.17973/MMSJ.2019_12_2019022

e-mail: tomas.holota@uniag.sk

The material of blanking tool was identified as one of the negative factors affecting high non-conformance and downtime in the blanking process. The aim of this paper was to choose a suitable alternative to the original material of blanking tool for achieving a longer operating tool life, and thus enhance the effectiveness and efficiency of the blanking process. Recommended materials by supplier were Caldie, K340 and K890. In decision-making process, we used modified decision matrix FDMM (Forced Decision Matrix Method) as appropriate method for objective and independent selection of new a material for blanking tool. When applying the statistical method, we considered criteria such as abrasion resistance, chipping resistance, reasonable material price for blanking tool and blanking speed. After the inclusion of mentioned new material of blanking tool, we achieved a yearly reduction of blank non-conformance from $2.62 \%$ to $0.05 \%$. We succeeded in reducing the production time of 1 blank from $1.1 \mathrm{~s}$ to $0.9 \mathrm{~s}$.

KEYWORDS

electro-slag remelting steel, blanking process, blanking tool, FDMM method, materials

\section{INTRODUCTION}

Fine-blanking process is one way of material dividing. Fineblanking can achieve flatness and cut edge characteristics that are unobtainable by conventional stamping and punching methods. Fine blanking process works on the principle of press techniques and employs special press, precision tool and dies. Through this process, parts are produced in almost completed form and ready for assembly operation. Apart from this, parts are produced with cleanly sheared surfaces over the entire material thickness. The sheared surface obtained by this process is of good quality and high dimensional accuracy.

Fine blank parts are generally made from materials in a relatively hard condition to obtain a good shear break characteristic. On contrary, fine blanking process requires materials that exhibit a good cold forming quality. Materials that can be fine blanked include aluminium, brass, copper, carbon, alloy, carbon steels and stainless steels.

In case of metal it begins with elastic, then plastic deformation and after local exhaustion of plasticity it ends with shearing deformation. A tool belonging to the group of expensive tools is used in blanking process. They are highly expensive to manufacture however it is compensated by their effectiveness and efficiency in mass-production.

Increasing the durability and operating life of blanking tools is a very topical, complex and important priority for organizations engaged in material blanking. When choosing a material, it is important to consider operating life and durability properties where we assess abrasion resistance and chipping resistance. Last but not the least, it is important to assess the economic efficiency taking into account the reasonable material price of blanking tool and blanking speed. Operating life is particularly important for blanking tools for their widespread use in practice. In the blanking process are blanking tools maximally affected by the wear of functional parts of blanking tool. In this case, the wear occurs faster than with other basic pressing operations.

Nowadays there are many statistical methods in decisionmaking process which represent a set of rules and procedures in order to achieve the right decision. If we use the distribution based on correlation between empiricism and theory contained in the individual methods, it is possible to divide them into three groups - empirical, heuristic and exact methods [Magdolenová 2007].

There are more different methods which have basically the same principle - assessment of several solution variants of defined problem according to selected criteria and ranking of alternatives. The various methods differ depending to how is assigned the weight of individual criteria and how is numerically assessed the degree by which individual alternative solutions fulfil the selected criteria [Titko 2016].

The aim of submitted paper is to choose a suitable alternative to the original material of blanking die for achieving a longer tool life, and thus enhance the effectiveness and efficiency of the blanking process. The supplier provided alternative materials $\mathrm{K} 340$ and $\mathrm{K} 890$ which are suitable for cold pressing. We decided to apply modified decision matrix FDMM as the appropriate method for the objective and impartial selection of new material for blanking tool.

\section{MATERIAL AND METHODS}

In case of fine cutting in the pressing process, a blanking tool is used (Fig. 1). The guide with guides is intended to ensure that the lower (fixed / stationary) and upper (movable) parts of the tool are aligned. The use of guiding elements ensures the production of components with high strength and quality of the shearing surface.
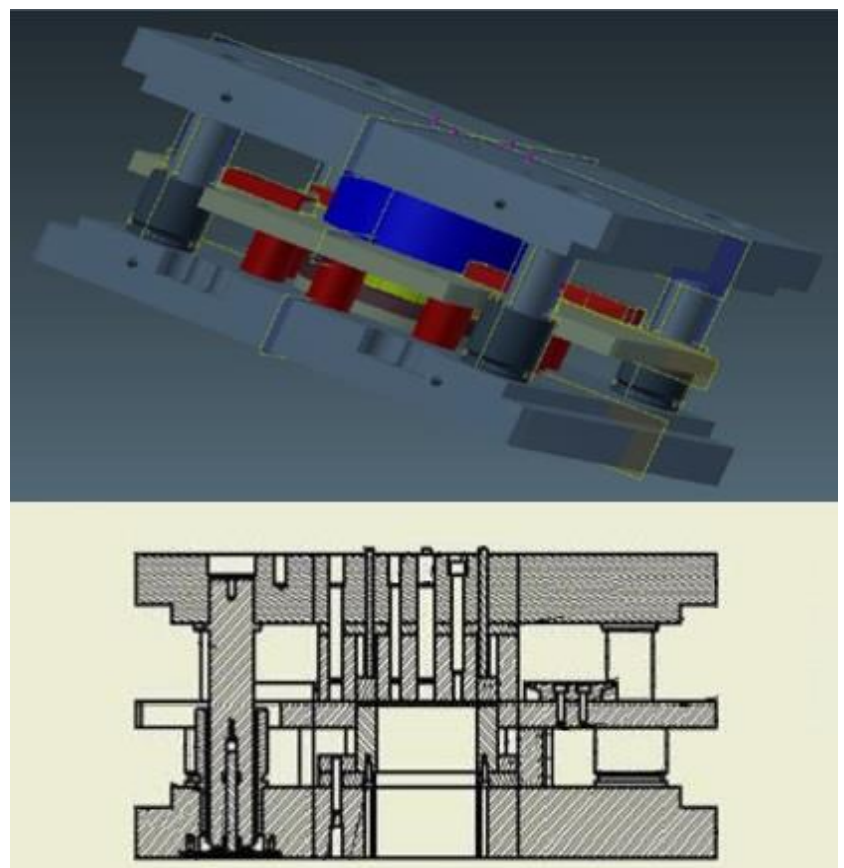

Figure 1: 3D/2D Model of Blanking Tool 


\subsection{Materials}

Blanking tool consists of two main parts, a punch and a matrix. The matrix fulfill the bottom function of the hard knife and the punch fulfill the upper function of the knife, the cutting press tool. At the same time, there are guiding elements: guide plate, guide posts and column guide sleeves.

The origin material of pressing tool steel is an alloy steel composed of $\mathrm{Cr}-\mathrm{Mo}-\mathrm{V}$ with mark Caldie from producer Böhler-Uddeholm SLOVAKIA, s.r.o. Caldie belongs to the category of electro-slag remelting steel. There is a change during the metallurgical process of electro slag remelting which leads to reduction of the proportion, size and to uniformity of distribution of non-metallic admixture. At the same time, this process positively affects the homogeneity of the chemical composition and grain distribution in the longitudinal and transverse direction.

Uddeholm-Caldie is a chromium-molybdenum-vanadium alloyed tool steel which is characterized by:

- very good chipping and cracking resistance,

- good wear resistance,

- high hardness ( $>60 \mathrm{HRC}$ ) after high temperature tempering,

- good dimensional stability in heat treatment and in service,

- excellent through-hardening properties,

- good machinability and grindability,

- excellent polishability,

- good surface treatment properties,

- good resistance to tempering back,

- very good WEDM properties.

Uddeholm - Caldie is suitable for short to medium run tooling where chipping and/or cracking are the predominant failure mechanisms and where a high compressive strength (hardness above $60 \mathrm{HRC}$ ) is necessary. This makes Uddeholm-Caldie an excellent problem solver for severe cold work applications where the combination of a hardness above $60 \mathrm{HRC}$ and a high cracking resistance is of utmost importance e.g. as in the blanking and forming of ultra-high strength steel sheets.

Böhler - Material K340 is a conventionally melted, oil- and airhardened $8 \%$ chromium steel with improved matrix structure and with good dimensional stability. $\mathrm{K} 340$ is produced using the electro-slag remelting (ESR) method. This by BÖHLER developed and proven remelting technology, ensures extremely low micro and macro segregations and gives the material the purity and homogeneity necessary for excellent performance in practice. It is specially designed tool steel for cold work.

Characteristic properties of material K340:

- outstanding toughness with excellent compressive strength,

- high abrasive resistance achieved by special alloying admixtures,

- excellent adhesive wear resistance,

- safety against breakage or failure in use,

- reproducible tool parameters,

- very well nitridated in the bath, in the gas and plasma,

- suitable for PVD coating,

- hardenable in vacuum.

Böhler - Material K890 is made by a powder metallurgical, is suitable for cold-working with superior plasticity and a high fatigue limit. This powder-metallurgical cold-working steel has good toughness, very good compressive strength, and excellent fatigue strength.

It is mainly used for special cold work tools working at high working loads with very high stability of cutting edges and high toughness, suitable for example for punches and matrices for fine cutting/blanking, cold forming such as embossing (coining), cold massive forming, powder compaction, injection moulding and forging at lower temperatures.

Characteristic properties of material K890:
- good fatigue strength,

- high ductility,

- high resistance to the fatigue of a material,

- good wear resistance,

- good thermal stability,

- lower burst resistance.

\subsection{Statistical methods}

There are several different methods that essentially have the same principle - to consider several variants of the solution to the given problem according to the chosen criteria and to determine the order of the variants. The different methods differ depending on how the so-called " the weighting of individual criteria and how numerically assesses the degree to which each solution variant meets the criteria selected.

We decided for FDMM method at the request of eliminating of subjective interferences in the material selection, it means to choose the requested material by exact way.

Procedure for application of FDMM method:

1. Determine compared material properties (criteria) and write down to the table.

2. Carry out pairwise criteria comparison in matrix which is transformed into table form. When comparing of criteria, more important criterion is evaluated by " 1 " and less important criterion is evaluated by " 0 ".

3. On the basis of comparison criteria assign the appropriate weights to the criteria.

weight $_{n}=\frac{\sum_{n=1}^{n} H_{n}}{\sum_{k=1}^{k} \sum_{n=1}^{n} H_{n}}$

Where: $H_{n}$ - value of criterion,

$\mathrm{n}$ - number and sequence number of criterion,

$\mathrm{k}$ - sequence number of criterion evaluation.

4. Create a decision matrix for assessing variant of materials for each criterion separately.

5. Compare the variants with respect to a particular criterion. More important criterion evaluate by "1" and less important criterion evaluate by " 0 “.

6. On the basis of variants comparison determine the appropriate values using the equation.

$H_{v}=\frac{\sum_{i=1}^{i} H_{v i}}{\sum_{j=1}^{j} \sum_{i=1}^{i} H_{v i}}$

Where: $H_{v i}-$ value of variant,

$i-$ number and sequence number of variant,

$\mathrm{j}$-sequence number of variant evaluation.

7. Create a decision table of calculated weights and variants evaluation.

8. Determine weighted sum $\left(S_{v}\right)$ using the equation:

$S_{v}=\sum_{n=1}^{n}$ weight $_{n} \times H_{v}$

Where: weight $_{n}$ - value of weight,

$\mathrm{H}_{\mathrm{v}}$ - value of variant,

$\mathrm{n}$ - number and sequence number of criterion.

9. Determine the order of variants based on calculated weighted sum. 


\section{RESULTS AND DISCUSSION}

When selecting of alternative materials, we considered following material properties:

- high abrasive resistance,

- very good chipping resistance,

- adequate price compared to the original material.

After consultation with the supplier we selected to the shortlist Caldie material (the current material), K340 and K890. In case of new materials $\mathrm{K} 340$ and $\mathrm{K} 890$, they represent suitable materials for blanking press tools in cold work conditions. K340 material is similarly as Caldie electro-slag remelting steel, straight intended for cold work. The main difference of material $\mathrm{K} 890$ to others is in production process - using powder metallurgy technology of 3rd generation. These steels are characterized by excellent dimensional stability, fine-grained structure and practical isotropic properties. More detailed properties of all three materials are presented in Tab. 1.

Table 1. Comparison of Material Properties of Tool

\begin{tabular}{|l|l|l|l|}
\hline & Caldie & K340 & K890 \\
\hline $\begin{array}{l}\text { Weight loss in the test } \\
\text { (mg.min }\end{array}$ & 108 & 83 & 62 \\
\hline Chipping resistance & $\begin{array}{l}\text { highly } \\
\text { resistant }\end{array}$ & $\begin{array}{l}\text { moderately } \\
\text { resistant }\end{array}$ & resistant \\
\hline $\begin{array}{l}\text { Price compared to the } \\
\text { original material in } \\
\text { EUR }\end{array}$ & 494.5 & 686.25 & $3,890.47$ \\
\hline $\begin{array}{l}\text { Blanking speed } \\
\text { (m.min-1) }\end{array}$ & $15-20$ & $15-20$ & $17-23$ \\
\hline Hardness HRC & 58 & 63 & 64 \\
\hline
\end{tabular}

When selecting of material variants, we applied multi-criteria method FDMM. Firstly, we assigned weights according to pairwise criteria comparison in Tab. 2.

The required properties from Tab. 1 we marked in ascending order by criteria $1-5(C 1-5)$ and assessed materials we identified as variants $1-3$ (V1 - 3). It means that when comparing of two criteria is more important (more important for decision making) criterion evaluated as " 1 " and less important criterion as " 0 “.

Table 2. Pairwise Criteria Comparison

\begin{tabular}{|l|l|l|l|l|l|l|l|}
\hline Criterion & C1 & C2 & C3 & C4 & C5 & Sum & Weight \\
\hline C1 & - & 1 & 0 & 1 & 1 & 3 & $\mathbf{3} / 10=0.3$ \\
\hline C2 & 0 & - & 0 & 1 & 1 & 2 & $\mathbf{2} / 10=0.2$ \\
\hline C3 & 1 & 1 & - & 1 & 1 & 4 & $\mathbf{4} / 10=0.4$ \\
\hline C4 & 0 & 0 & 0 & - & 0 & 0 & $\mathbf{0} / 10=0$ \\
\hline C5 & 0 & 0 & 0 & 1 & - & 1 & $\mathbf{1 / 1 0}=\mathbf{0 . 1}$ \\
\hline
\end{tabular}

We applied a similar evaluation procedure in variants material evaluation of tools for each selected criterion separately. Compared variants of materials were evaluated " 1 " if better met the selected criterion and " 0 " if worse met the selected criterion. Pairwise variants comparison is presented in Tab. 3-7.

Table 3. Pairwise Variants Comparison According to Criterion C1

\begin{tabular}{|l|l|l|l|l|l|}
\hline Variant & V1 & V2 & V3 & Sum & Evaluation \\
\hline V1 & - & 0 & 0 & 0 & $0 / 3=0$ \\
\hline V2 & 1 & - & 0 & 1 & $1 / 3=0.333$ \\
\hline V3 & 1 & 1 & - & 2 & $2 / 3=0.667$ \\
\hline
\end{tabular}

Table 4. Pairwise Variants Comparison According to Criterion C2

\begin{tabular}{|l|l|l|l|l|l|}
\hline Variant & V1 & V2 & V3 & Sum & Evaluation \\
\hline V1 & - & 1 & 1 & 2 & $2 / 3=0.667$ \\
\hline V2 & 0 & - & 1 & 1 & $1 / 3=0.333$ \\
\hline V3 & 0 & 0 & - & 0 & $0 / 3=0$
\end{tabular}

Table 5. Pairwise Variants Comparison According to Criterion C3

\begin{tabular}{|l|l|l|l|l|l|}
\hline Variant & V1 & V2 & V3 & Sum & Evaluation \\
\hline V1 & - & 1 & 1 & 2 & $2 / 4=0.5$ \\
\hline V2 & 1 & - & 1 & 2 & $2 / 4=0.5$ \\
\hline V3 & 0 & 0 & - & 0 & $0 / 4=0$ \\
\hline
\end{tabular}

Table 6. Pairwise Variants Comparison According to Criterion C4

\begin{tabular}{|l|l|l|l|l|l|}
\hline Variant & V1 & V2 & V3 & Sum & Evaluation \\
\hline V1 & - & 0 & 0 & 0 & $0 / 3=0$ \\
\hline V2 & 1 & - & 0 & 1 & $1 / 3=0.333$ \\
\hline V3 & 1 & 1 & - & 2 & $2 / 3=0.667$ \\
\hline
\end{tabular}

Table 7. Pairwise Variants Comparison According to Criterion C5

\begin{tabular}{|l|l|l|l|l|l|}
\hline Variant & V1 & V2 & V3 & Sum & Evaluation \\
\hline V1 & - & 0 & 0 & 0 & $0 / 3=0$ \\
\hline V2 & 1 & - & 0 & 1 & $1 / 3=0.333$ \\
\hline V3 & 1 & 1 & - & 2 & $2 / 3=0.667$ \\
\hline
\end{tabular}

On the basis of Tab. $3-7$, in which we detected the values of weights of individual criteria using a pairwise criteria comparison in which we also evaluated pairwise comparison of material variants with respect to individual criteria. Subsequently we created Tab. 8.

Table 8. Decision Table of Method FDMM

\begin{tabular}{|c|c|c|c|c|}
\hline \multirow{2}{*}{ Criteria } & \multirow{2}{*}{ Weight } & \multicolumn{3}{|c|}{ Evaluated material variants } \\
\hline & & Caldie & K340 & K890 \\
\hline $\begin{array}{l}\text { Weight loss in the test } \\
\left(\mathrm{mg} \mathrm{min}^{-1}\right)\end{array}$ & 0.3 & 0 & 0.333 & 0.667 \\
\hline Chipping resistance & 0.2 & 0.667 & 0.333 & 0 \\
\hline $\begin{array}{l}\text { Price compared to the } \\
\text { original material in } \\
\text { EUR }\end{array}$ & 0.4 & 0,5 & 0,5 & 0 \\
\hline $\begin{array}{l}\text { Blanking speed } \\
\left(\mathrm{m} \cdot \mathrm{min}^{-1}\right)\end{array}$ & 0 & 0 & 0.333 & 0.667 \\
\hline Hardness HRC & 0.1 & 0 & 0.333 & 0.667 \\
\hline Weighted sum & & 0.333 & 0.400 & 0.267 \\
\hline Order & & 2. & 1. & 3. \\
\hline
\end{tabular}

As we can see from Table 8, after consideration of weights and values of individual variants with using and comparing of weighted sum, we received the ranking of individual variants of material. In the first place in evaluation was placed material K340 followed by material Caldie, which is currently used. In the third place in evaluation was placed new material K890, whose position was greatly affected by high price of this material what ultimately results in low economic efficiency in blanking process.

Material K340 is specially designed tool steel for cold work, produced by electro-slag remelting. $\mathrm{K} 340$ is applicable in many processes, for example blanking, cutting, cold rolling, extruding, deep drawing, bending. In applications where materials with 
good wear resistance and compressive strength coupled with excellent toughness are required, K340 has proved itself to be the all-rounder among tool steels. This material thanks to the chemical composition and the manufacturing process, this steel has finer and more evenly distributed carbides than ledeburitic $12 \%$ Cr-steels (AISI D2) and conventional 8\% Cr-steels. This gives the steel its improved toughness properties.

Advantages compared to material Caldie:

- more homogeneous structure over the whole cross section and length,

- possibility of manufacturing of tools in larger dimensions,

- dimensional stability or minimal dimensional changes,

- wider range of fields of application due to the outstanding toughness,

- optimal for more critical tool geometry due to high compressive strength,

- really good machinability due to homogeneous structure.

For powder metallurgy (PM), excellent compressive strength and hardness results from the presence of a large weight fraction of metal carbides in the microstructure, owing to the addition of tungsten, molybdenum, chromium, and vanadium to around 30\% of the weight [Satya Prasad 1997, Godec 2010]. Compared to the conventional casting method, element segregation during solidification can be eliminated and an ultrafine grain can be obtained in the PM process because the cooling rates of the gas atomized powders reach 105-106 K/s [Wiessner 2008]. However, the PM route is a relatively complicated process, which has high costs associated with powdering and hot isostatic pressing (HIP) [Tornberg 2002]. HIP has been shown to improve the density of PM and spray formed materials, which is beneficial to increase service life and fatigue performance under severe working conditions.

Electro-slag remelting (ESR) is widely used for the production of high-value-added alloys such as special steels or nickel-based superalloys [Weber 2009].

Electro-slag remelting (ESR) has been developed to produce high-performance alloys dedicated to critical applications for which high-metallurgical-quality ingots are necessary. Consequently, primary melting is not sufficient; remelting, on the other hand, provides valuable advantages, such as a fine solidification structure, limited occurrence of solidification defects, low levels of micro- and macrosegregation, and sound ingots. Moreover, insulation from air and chemical refining due to the presence of slag improve the inclusional quality [Duckworth 1969].

Statistical evaluation of input data is one of the most important procedures for monitoring of manufacturing processes in organization and the results are used for statistical regulation and continuous improvement of the process. Process capability to meet technical requirements as well as customer requirements or by organization sets desired values and tolerance limits indicates the capacity of the manufacturing process [Hambálková 2016].

Part of improving proposals of process must include evaluation of irremovable hazards and risks resulting from the proposed solutions in intended operating and usage conditions as well as assessment of risk during their using and proposal of protective measures against these hazards [Hoyle 1983].

In case of FDMM method we discuss about modified decision matrix (FDMM - Forced Decision Matrix Method). Decision matrix provides an effective way how to prioritize a particular item among the large number of competing items.

It is a statistical process by which we compare the items on an individual basis on every other item with favouring one over the other. Prioritisation is defined by weights [Bhushan 2004].

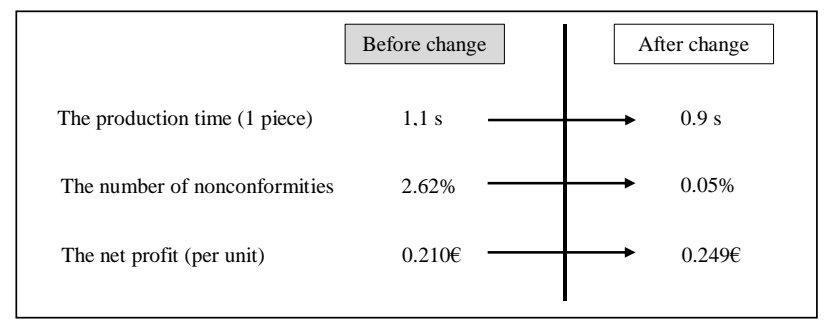

Figure 2: 3D/2D Model of Blanking Tool

The Fig. 2 presents the situation before and after the change when we have chosen new material for blending tool by using statistical method of independence choice.

\section{CONCLUSIONS}

Fine-blanking technology (technology of cold pressing) began to use later than the other conventional methods of cutting. With this cutting method, it is possible to obtain a product of high precision ranging from IT6 - IT11 according to the thickness of the product and good perpendicularity and roughness of the cutting-edge surface in the range of Ra 0.4-1.6. The cut-out cutout does not require any additional surface treatment and can be used immediately, what ensure saving additional machine operations and reduce overall production time.

The aim of this paper was to choose an alternative material of blanking die for achieving a longer tool life, and thus enhance the effectiveness and efficiency of the blanking process.

After consultation with the supplier, we chose Caldie (current material), K340 and K890. In the case of new K340 and K890 materials, these materials are suitable for die-casting tools in cold working conditions. The $\mathrm{K} 340$ is similar to Caldie's electrically-melted steel; on the other hand, the steel is directly designed for cold work. The main difference with K890 materials is the production method by using the thirdgeneration powder metallurgy technology. These steels feature perfect dimensional stability, fine-grained structure and virtually isotropic properties.

When choosing the right material, we applied decision matrix FDMM. For the FDMM method, we decided on the base of requirement, to eliminate the subjective interventions in the material selection process and thus to select the required material in the exact way.

The result of chosen statistical method was to determine the order of compared materials Caldie, K340 and K890. In the first place with best results was placed material K340. Due to the result of analysis we used material K340 as a new material of blanking die.

After applying the K340, we have achieved an even longer tool life, which was caused to higher abrasion, adhesive and fatigue resistance towards the original Caldie material. By reducing the number of downtime needed to repair the blanking tool after wear and tear cutting, we have been able to reduce the production time of 1 piece of product from $1.1 \mathrm{~s}$ to $0.9 \mathrm{~s}$, while making an annual production of approximately 250000 pieces approximately 13.9 hours saving time from the total time required to produce approximately 76.4 hours, what it represents a decrease of $18.2 \%$. By selecting material with better character properties, we are managed to reduce the number of nonconformities from $2.62 \%$ to $0.05 \%$ year on year. At the same time, we managed to increase the net profit per unit of product from its original value of $€ 0.210$ to $€ 0.249$, which represents an increase in net profit of $18.6 \%$ year-onyear. 


\section{REFERENCES}

[Bhushan 2004] Bhushan, N. and Rai, K. Strategic decision making: Applying the Analytic Hierarchy Process. London: Springer-Verlag, 2004. ISBN 978-1-85233-864-0

[Duckworth 1969] Duckworth, W.E. and Hoyle, G. Electro-slag refining. London: Chapman and Hall, 1969. ISBN 978-0-47022358-1

[Godec 2010] Godec, M., et al. Characterization of the carbides and the martensite phase in powder-metallurgy high-speed steel. Materials characterization, 2010, Vol. 61, No. 4, pp. 452458. ISSN 1044-5803

[Hambalkova 2016] Hambalkova, M. and Kadekova, Z. Current state and strategy of development of the Slovak foreign trade until 2020. In: Marketing management, trade, financial and social aspects of business, 2016. Bratislava: University of Economics, pp. 47-52. ISBN 978-80-225-4293-7

[Hoyle 1983] Hoyle, G. Electroslag processes: principles and practice. Mishawaka: Applied Science Publishers, 1983. ISBN 978-0-85334-164-2

[Magdolenova 2007] Magdolenova, J. Empirical Methods of Decision Making in Management. Scientific Papers of the University of Pardubice, 2007, Vol. 13, No. 11., pp. 192-196. ISSN 1211-555X

\section{CONTACTS}

Ing. Tomas Holota, PhD.

Department of building equipment and technology safety Faculty of Engineering

Slovak University of Agriculture in Nitra

Tr. A. Hlinku 2, Nitra 949 76, Slovakia

tel.: +421 37641 4300, e-mail: tomas.holota@uniag.sk
[Satya Prasad 1997] Satya Prasad, V.V., et al. Hot ductility of an electroslag crucible melted age hardenable $\mathrm{Cu}-\mathrm{Cr}$ alloy. Materials Science and Technology, 1997, Vol. 13, No. 10., pp. 872-874. ISSN 0267-0836

[Titko 2016] Titko, M. and Byrtusova, A. Transport network vulnerability determination using multicriteria decision-making. Perner's Contacts, 2016, Vol. 11, No. 1., pp. 181-191. ISSN 1801-674X

[Tornberg 2002] Tornberg, C. and Folzer, A. New optimised manufacturing route for PM tool steels and high speed steels. In: Proceedings of the 6th International Tooling Conference: The Use of Tool Steels: Experience and Research, 2002. Karlstad: Karlstad University, pp. 305-316. ISBN 978-918-942282-7

[Weber 2009] Weber, V., et al. A Comprehensive Model of the Electroslag Remelting Process: Description and Validation. Metallurgical and Materials Transactions, 2009, Vol. 40, No. 3., pp. 271-280. ISSN 1073-5615

[Wiessner 2008] Wiessner, M., et al. Phase transformation study of a high speed steel powder by high temperature X-ray diffraction. Materials characterization, 2008, Vol. 59, No. 7., pp. 937-943. ISSN 1044-5803. 